\title{
Determination of alpha-Tocopherol Acetate in an Anti-Aging Cosmetic Cream by Gas Chromatography
}

\author{
ANCA MARIA JUNCAN*, LUCA LIVIU RUS, FELICIA GABRIELA GLIGOR, CLAUDIU MORGOVAN \\ Lucian Blaga University, Faculty of Medicine, Preclinical Department, 2A Lucian Blaga Str., 550169, Sibiu, Romania
}

\begin{abstract}
A gas chromatographic method was applied by using the GC-FID tehnique for the determination of $\alpha$ tocopherol acetate in an anti-aging properly developed cosmetic formulation. A simple methanol:acetonitrile organic solvent mixture (50:50v/v) was required for sample preparation and the separation of the studied compound was carried out in specific chromatographic conditions. The analysis was carried out in proper developed anti-aging cream sample and satisfactory results were obtained for the recovery of the studied compound.
\end{abstract}

Keywords: anti-aging cosmetic product, antioxidants, á-tocopherol acetate, GC-FID

Skin aging is characterized by a progressive deterioration of the skin's functional properties, linked to alterations of dermal connective tissue due to the changes at the cell, gene and protein levels [ 1,2$]$.

Aging affects all levels of the skin. From the stratum corneum downwords aging creates corneocyte dysfunction, epidermal atrophy, dysplasia and abnormal pigmentation (fig. 1.) [3]. Aging occurs in all organs of the body; however, the skin appearance, such as wrinkles and furrows, is markedly observed for aging notices. It is a challenging work for cosmetic scientists to find the means for reducing the changes on the skin appearance due to aging. Application of cosmetic products containing oils with antioxidant activity is widely acceptable to benefit healthy skin [4].

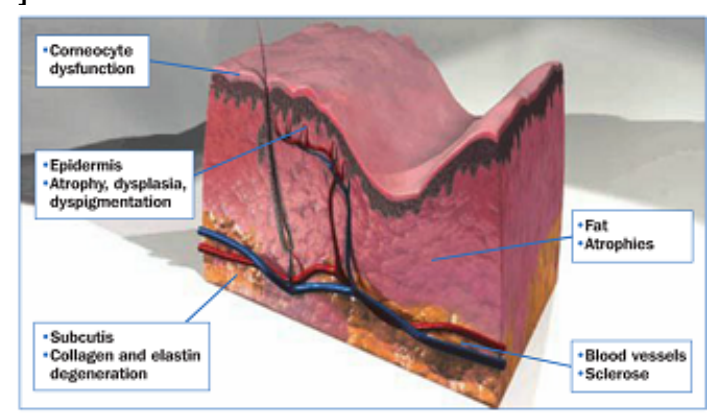

Fig. 1. Skin levels affected by ageing

Skincare products that affect wrinkles are a reality and are well established in consumer, practitioner and corporate perspectives. In the broadest definition, products range from classic and simple cosmetic preparations through vitamins, antioxidants, topical and oral cosmeceutical and pharmaceutical preparations, and even to surgical and laser interventions [5].

Cosmetological research has increasly focused on process leading to the formation of anatomical-functional damage to the skin $[6,7]$, identified with ageing. At the same time, every possible means to counteract the injurious effects have been evaluated. Greatinterest in this topic has been aroused by the study of substances able to prevent cutaneous damage by free radicals: these substances are currently named as antioxidants [8].

The expanding range of natural actives in mainstream cosmetic products thatsupporthealthyskin aging, is ample proof that the industry now relies heavily on these ingredients [9]. Inclusion of botanical extracts such as vitamins and anti-microbials to cosmetics has become an important marketing advantage [10]. Pure natural compounds or plant total extract represent a wellspring of remedies for a variety of pathologies [11].

The free radicals induced oxidative stress has been reported to be involved in several diseasesd conditions such as diabetes mellitus, hypertension, hyperlipidemia or dermatological diseases [12].

The use of antioxidants in any anti-aging skin care regimen is essential in order to combat and prevent further damage. Vitamins have been used to combat free radical damage for many years. Some antioxidants have protective benefits while others work as protectants in addition to stimulating age-reversal changes. Topically applied vitamin $E$ plays an enormous role in protecting the skin from free radical damage [13].

Vitamin $E$ is a fat-soluble vitamin, which in its most potent form is known as $\alpha$-tocopherol. It has multifunctional benefits. It most commonly is used in multifunctional cosmeceutical products as a moisturizer, and as a stabilizer for other ingredients against oxidation. Research shows that vitamin E has additional benefits for the skin: it is necessary to stabilize cell membranes; it is thought to control parameters impacting the structure and function of various lipoproteins; and its antioxidant effects are thought to be protective against substances that may have damaging effects on the skin.

Vitamin E can be modified into an ester form, and the most popular ester used in cosmetics and cosmeceuticals is vitamin $E$ acetate (fig. 2.), a compound that is very stable against oxidation $[14,15]$.

Clinically, vitamin $E$ reverses photoaging dramatically, decreasing unattractive wrinkles and solar lentigos [1618].

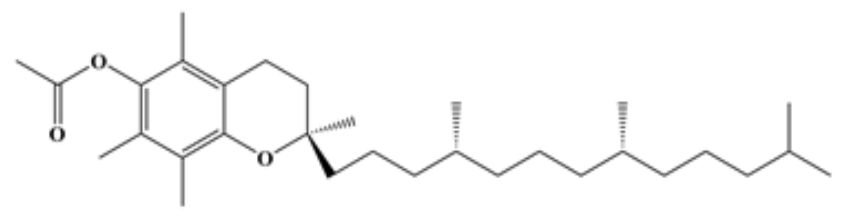

Fig. 2. Structure of $\alpha-\mathrm{TA}$ 
Several components of a cosmetic formulation are able to interact with active ingredients (volatile oils, pigments, antioxidants, etc.), reducing their stability and efficacy. It is important to determine the activity of antioxidants and their long term stability in the final formulations [19].

Matrix of anti-aging cosmetics is very complex, usually containing a high number of ingredients. Determination of antioxidant compounds from cosmetics is often difficult due to the matrix complexity, therefore greatattention must be devoted to developing suitable extraction procedures and reliable evaluation of the mean recovery values. The procedure used to extract antioxidants from cosmetics depends on the nature of the formulation and also on the features of the analytical techniques employed for the determination of active substances. That why it is necessary to develop performant methods of analysis, that can exactly and with precission determine the type and amount of antioxidants present in cosmetic products [20].

Cosmetic formulations contain very often mixtures of antioxidant preservatives belonging to different chemical classes and characterized by different functional groups. Therefore, multicomponent analysis methods are required. In this sense, chromatographic techniques are those most commonly used to determine antioxidants and preservatives in cosmetic products [21].

The evaluation of antioxidant components can be achieved through various analysis techniques [22-24]. The nature of the extraction solvent, the solid-to-solvent ratio and the extraction method determine the amount and type of extracted phenolic, and also the antioxidant activity of the extracts [25].

The objective of this study was the qualitative and quantitative determination of tocopherol acetate ( $\alpha$-TA) in an anti-aging cosmetic formula, by gas chromatography. The present study describes a method based on simple extraction procedure with organic solvent mixture of the studied antioxidant from an anti-aging cosmetic preparation prior to analysis by gas chromatography and FID detection.

\section{Experimental part}

\section{Materials and methods}

Preparation of the anti-aging cosmetic formulation

The ingredients used in the anti-aging cream formulation were: deionised water, isoamyl laurate, octyl methoxy- cinnamate, glyceryl stearate citrate, cetearyl alcohol, glyceryl caprylate, squalane (Biesterfeld Spezialchemie Romania S.R.L.), Camelia sinensis extract (Symrise AG, Holzminden, Germany), glycerin, cyclo-pentasiloxane, cyclohexasiloxane, butyl methoxy-dibenzoylmethane, Butyrospermum Parkii (Biesterfeld Spezialchemie Romania S.R.L.), hydrolyzed collagen (BASF SRL, Bucure-ti, Romania), dimethicone, caprylyl glycol, glyceryl caprylate, phenyl propanol, tocopheryl acetate, Helianthus Annuus Seed Oil, xanthan gum (Biesterfeld Spezialchemie Romania S.R.L.), parfum (CPL Aromas, Brixworth, UK), sodium polyacrylate (ISP, Koln, Germany), sodium phytate (Biesterfeld Spezialchemie Romania S.R.L.). Figure 3. shows the composition of the developed anti-aging cream.

\section{Manufacturing procedure}

Phase A (aquaous Phase) was heated up to $78^{\circ} \mathrm{C}$ and Sodium Polyacrylate and xanthan gum was dispersed. Phase $B$ was heated up to $78^{\circ} \mathrm{C}$. Phase $B$ was emulsyfied into Phase A under stirring and homogenized for 1-2 min., using an ultra turrax. Medium stirring was performed for cooling down. Phase C (Camelia sinensis extract and hydrolyzed collagen) and Phase D (parfum) were added below $40^{\circ} \mathrm{C}$ and cooling down was performed understirning.

In the developed anti-aging formulation, $\alpha$-tocopherol acetate $(\alpha-T A)$ is dissolved in sun flower oil, raw material that is commercialy denominated as Dermofeel ${ }^{\circledR} E 74 A$ (Biesterfeld Spezialchemie Romania S.R.L.). $\alpha$-TA concentration in Dermofeel ${ }^{\circledR}$ E74A claimed by the supplier is larger than $73.5 \%$. The quantitative formula of the Anti Aging Day Cream contains 0.5\% Dermofeel ${ }^{\circledR}$ E74A.

\section{GC-FID method}

Standards and reagents

All reagents used were of analytical grade and were used without further purification. Commercially available antioxidant used in the study is tocopheyl acetate (BASF $\mathrm{SRL}$, Bucuresti, Romania) and Dermofeel ${ }^{\circledR} \mathrm{E} 74 \mathrm{~A}$ (INCl: Tocopheryl Acetat) (Biesterfeld Spezialchemie Romania S.R.L.).

\section{Sample preparation}

The anti-aging cream was analyzed by dissolving $1.0 \mathrm{~g}$ of the o/w emulsion by sonication (HF-Freq. $35 \mathrm{kH}$, Transsonic T460, Elma GmbH\&CO) into $10 \mathrm{~mL}$ of

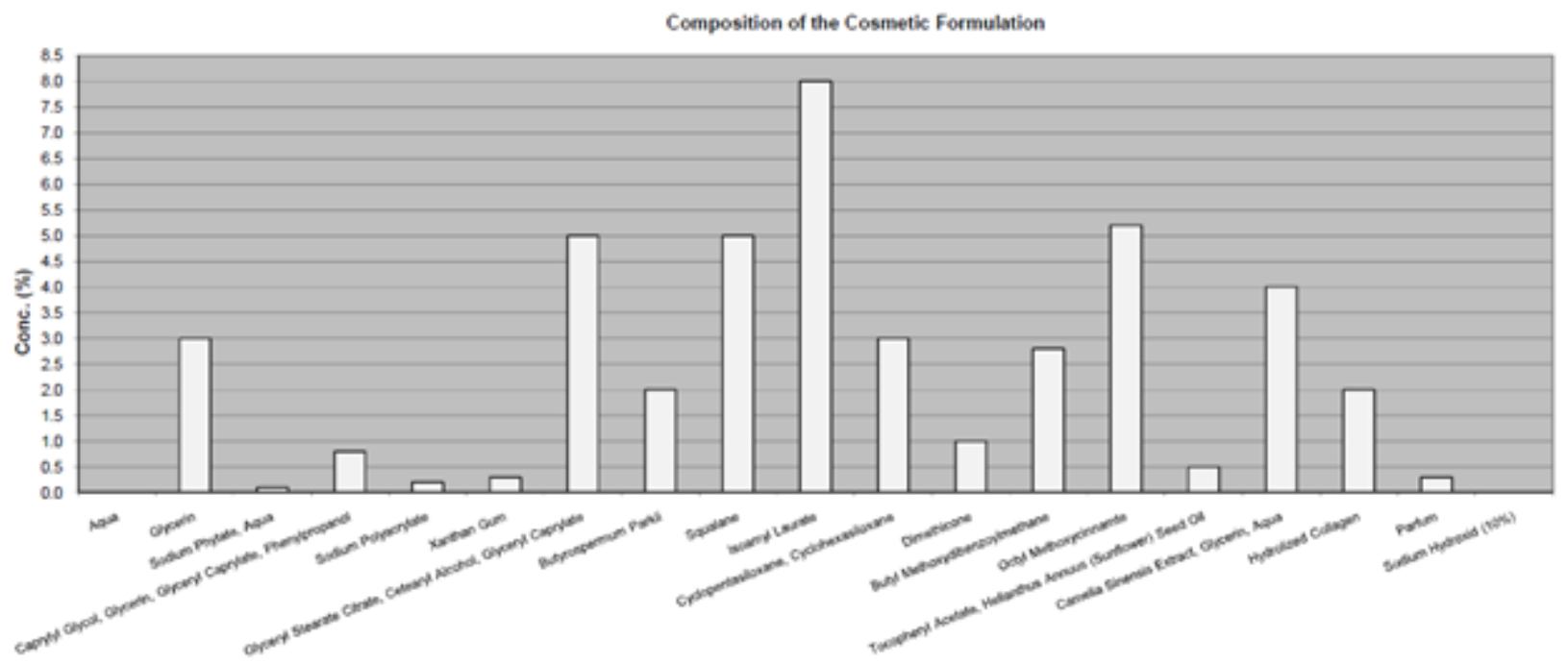

Fig. 3. Composition of the Anti-Aging Day Cream 
methanol:acetonitrile (50:50 v/v) organic solvent mixture. After centrifugation for $5 \mathrm{~min}$, the supernatant was filtered through a $0.45 \mu \mathrm{m}$ filter (Chromafil PET-45/25, $0.45 \mu \mathrm{m}$, Macherey-Nagel GmbH\&CO. KG.).

\section{Calibration curve of standard solution}

Stock solution were prepared by dissolving the appropiate amount of the standard antioxidant $(0.0500 \mathrm{~g}$ $\alpha-\mathrm{TA})$ in $10 \mathrm{~mL}$ methanol:acetonitrile (9:1 v/v) organic solvent mixture, transfered to a $50 \mathrm{~mL}$ volumetric flask and brought to volume. A set of working solutions was prepared by dilluting aliquots of the stock solution to give concentrations ranging from 150 to $1000 \mathrm{mg} / \mathrm{L}$ of the studied compound.

\section{Chromatographic conditions}

Chromatography was performed on a Shimadzu 2010 Model gas cromatograph equipped with a FID detector. Fused silica capillary column DB-5, 30m x $0.25 \mathrm{~mm} I D$, coated with a $0.25 \mu \mathrm{m}$ film of $5 \%$ diphenyl- $95 \%$ dimethylpolysiloxane, was used. The owen temperature was held at $120^{\circ} \mathrm{C}$ for five min, then increased at a rate of $10^{\circ} \mathrm{C} / \mathrm{min}$ to $310^{\circ} \mathrm{C}$ and held for $10 \mathrm{~min}$. Detector conditions were $320^{\circ} \mathrm{C}, \mathrm{N}_{2}-30 \mathrm{~mL} / \mathrm{min}$ and $\mathrm{H}_{2}-40 \mathrm{~mL} / \mathrm{min}$ flow-rate. The injection temperature was $35^{\circ} \mathrm{C}$. 1 il aliquots of the standard and sample solutions were injected and analyzed under the operation conditions described above.

\section{Results and discussions}

Good separation of $\alpha$-TA was obtained by GC analysis, having the retention characteristic of $t_{\text {pa-t }}=25.737 \mathrm{~min}$. On the basis of conducted experiment GC-FID method for the determination of $\alpha$-TA in an anti-aging cosmetic formula was established.
The standard solutions of the antioxidant were injected, to determine the individual retention time of the natural antioxidant. Figure 4 . shows the chromatogram of a 500 $\mathrm{mg} / \mathrm{L} \alpha$-TA standard solution.

The calibration curve for $\alpha$-TA was constructed over the covered range of concentration and is presented in figure 5. Calibration curve was constructed in order to study method liniarity. The linearity obtained was satisfactory and present a correlation coefficient of 0.999861 .

The detection limit (LOD) and quantitation (LOQ) expressed as signal $/$ noise $=3$ and signal/noise $=10$, were determined based on standard deviation through responses and the slope of regression equation of a curve constructed at following concentration levels: 150, 250, 350, 500, 750 and $1000 \mathrm{mg} / \mathrm{mL}$ for $\alpha-T A$. The obtained LOD value was 0.044 . There was calculated a LOQ of $0.134 \mathrm{mg} / \mathrm{mL}$.

The anti-aging cream sample was prepared in the laboratory by adding and $0.5 \%$ Dermofeel ${ }^{\circledR} \mathrm{E} 74 \mathrm{~A}(\mathrm{w} / \mathrm{w})$.

The analysed cream sample that contained the antioxidant was analysed and the target compound was identified by comparing the retention time of the observed peak with that obtained from the standard solution. The GC chromatogram of the Anti Aging Day Cream is presented in figure 6 .

The recovery, defined as (found concentration/spiked concentration) $\times 100 \%$, was calculated for the cream sample. The concentration of the antioxidant $\alpha$-TA determined from the cosmetic samples are listed in table 1. Complete triplicate analysis was performed on the cream sample to allow the calculation of average deviations as a measurement of chromatographic reproductibility.

Table 2 presents the concentration and recovery rate obtained for $\alpha$-TA in the cream sample.
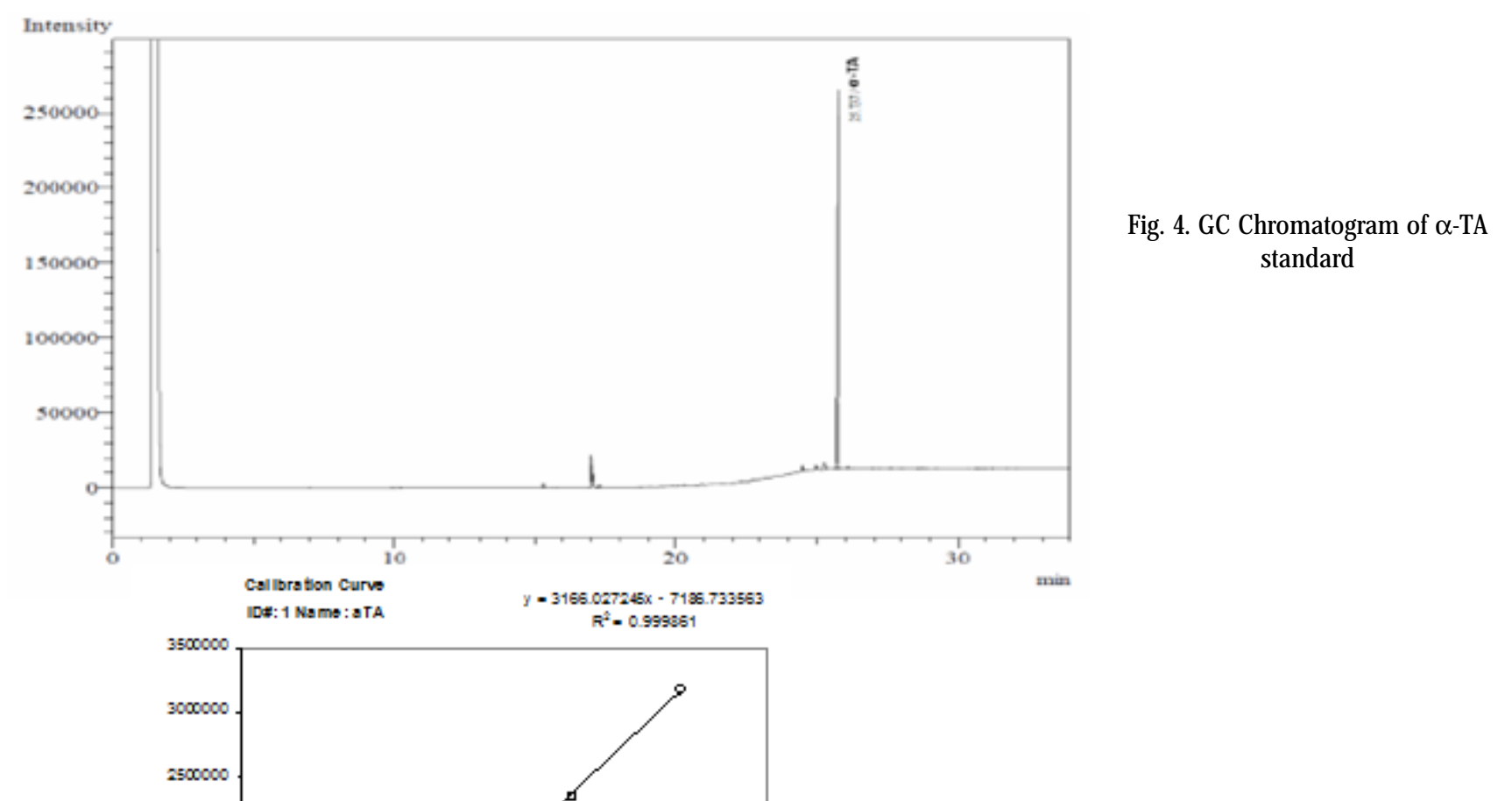

Fig. 5. Calibration curve of $\alpha$-TA 


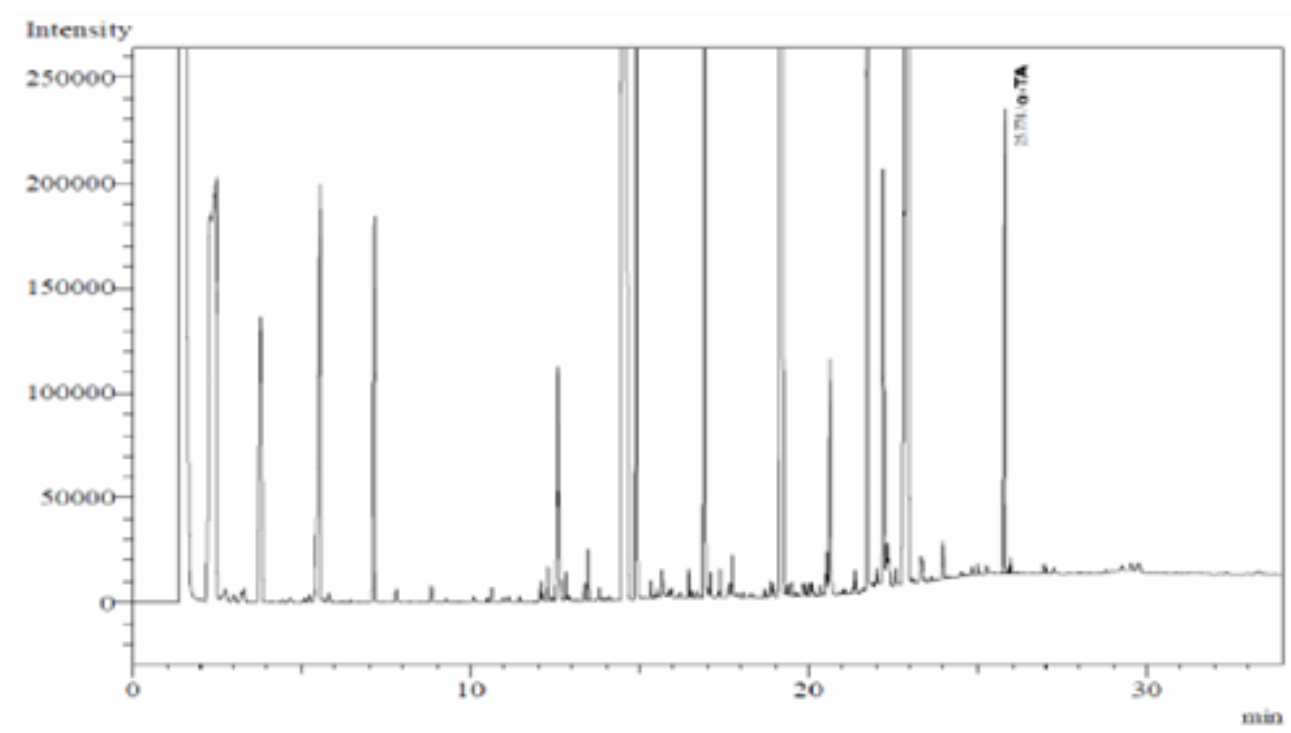

Fig. 6. GC Chromatogram of an Anti Aging Day Cream

Table 1

CONCENTRATION VALUES AND PEAK AREA OF $\alpha$-TA IN THE ANALYSED ANTI AGING DAY CREAM SAMPLE

\begin{tabular}{|c|c|c|c|c|c|c|}
\hline Nr. injection & $\begin{array}{c}\text { Concentration } \\
(\mathrm{mg} / \mathrm{L})\end{array}$ & $\begin{array}{c}\text { Average } \\
\text { Concentration } \\
(\mathrm{mg} / \mathrm{L})\end{array}$ & SD & RSD \% & Area & $\begin{array}{c}\text { Average } \\
\text { Area }\end{array}$ \\
\hline 1 & 177.94 & \multirow{3}{*}{177.17} & \multirow{3}{*}{0.002} & \multirow{3}{*}{0.5} & 557912 & \multirow{3}{*}{555492} \\
\hline 2 & 177.26 & & & & 555786 & \\
\hline 3 & 176.3 & & & & 552776 & \\
\hline$=3$ & & & & & & \\
\hline
\end{tabular}

Table 2

CONCENTRATION VALUE AND RECOVERY RATE OF $\alpha$-TA IN THE ANALYSED ANTI AGING DAY CREAM SAMPLE

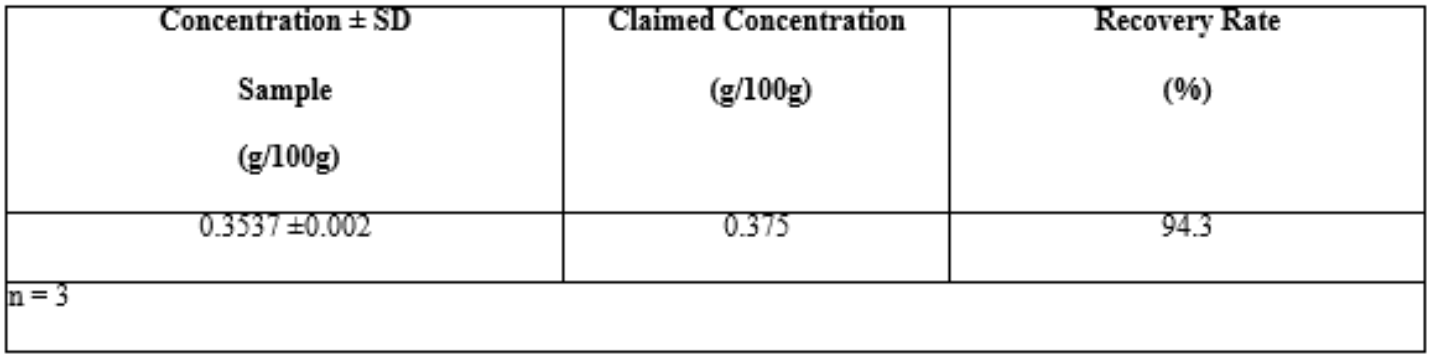

Good recovery of the $\alpha$-TA from the studied Anti Aging Day Cream was obtained with the used extraction and GC-FID method.

\section{Conclusions}

An Anti-aging day cream was developed and formulated.

A GC-FID method following a simple extraction with methanol:acetonitrile organic solvent mixture $(9: 1 \mathrm{v} / \mathrm{v})$ was used for the determination of $\alpha$-TA in the developed antiaging cosmetic formulation. Calibration curve of standard solution was linear in the range from 150 to $1000 \mathrm{mg} / \mathrm{mL}$ for the studied compound. Good recovery was obtained for the antioxidant by the used method. This method allowed a simple and accurate determination and confirmation of $\alpha$-TA in a anti-aging cosmetic product containing various ingredients. The described method presents good selectivity, adequate detection and quantitation limits and can be applied in the routine analysis for quality control of cosmetic preparations containg $\alpha$ TA.

\section{References}

1.KIM, Y. H., KIM, K. H., HAN, C. S., YANG, H. C., PARK, S. H., JANG, H.I., KIM, J.-W., CHOI, Y.-S., LEE N., J. Cosmet. Sci., 61, 2010, p. 211.

2.RAO, S., MUIA, F., BENNETT, S., GRUBER, J. V., Personal Care Magazine, 9, 2013, p. 77.

3.LOWE, N. J., Personal Care Magazine, 2, 2013, p. 17-22.

4.BOONME, P., H\&PCToday, 6, 1, 2011, p. 42.

5.BAREL, A., PAYE, M., MAIBACH, H. I., Handbook of Cosmetic Science and Technology, Marcel Dekker, New York, 2001, p. 543-544.

6.JUNCAN, A. M., RUS, L. L., Mat. Plast., 55, no. 3, 2018, p. 426.

7.JUNCAN, A. M., Mat. Plast., 55, no. 4, 2018, p. 644.

8.ANDREASSI, M., ANDREASSI, L., J. Cosmetic Dermatol., 2, 2004, , 153-160.

9.PRAKASH L., MAJEED M., Household and Personal Care TODAY, 2009, 2, p. 44.

10.NADA, A., KRISHNAIAH, Y. S. R., ZAGHLOUL, A.-A., KHATTAB, I., J. Cosmet. Sci., 61, 2010, p. 353.

11.DANCIU, C., BIRIS, M., BALÁZS, B., CSÁNYI, E., PAVEL, I. Z., POP, G., SOICA, C., CEUTA, L., NITA, L., MORGOVAN, C., STOIAN, D., Rev. Chim. (Bucharest) 66, no. 7, 2015, p. 1038. 
12.GHIBU S., DECEA N., MORGOVAN C., MOGOa AN C., FARMACIA, 61, 2, 2013, p. 420.

13.BURGESS, C. M., Cosmetic Dermatology, Springer Verlag, Heidelberg, 2005, p. 19-22.

14. SCHULLER, R., ROMANOWSKI, P., Multifunctional Cosmetics, Marcel Dekker, New York, 2003, p. 134-140.

15. LING, S., Personal Care Magazine, 5, 2013, p. 67.

16. BURKE, K. E., J. Cosm. Dermatol., 3, 2004, p. 149.

17. PAPPAS, A., Nutrition and Skin. Lessons for Anti-Aging, Beauty and Healthy Skin, Springer, New York, 2011, p. 52-55.

18.MING, K. Y., Personal Care Magazine, 11, 2017, p. 89.

19.J UNCAN, A. M., FETEA, F., SOCACIU, C., ENVIRON. ENG. MANAG. J., 13,1, 2014, p. 105.
20. JUNCAN, A. M., HODI'AN, T., Rev. Chim. (Bucharest), 62, no. 4, 2011, p. 415.

21.JUNCAN, A. M., HORGA, E. C., HODISAN, T., Studia UBB Chemia, 56, 2, 2011, p. 195-204.

22.TAMPA, M., NICOLAE, I., ENE, D. C., SARBU, I., MATEI, C., GEORGESCU, Rev. Chim. (Bucharest), 68, no. 1, 2017, p. 43.

23.HANGANU, D., FILIP, L., OLAH, N.-K., MOCAN, A., VLASE, L., RAITA, O., ONIGA, I., BENEDEC, D., FARMACIA, 64, 6, 2016, p. 863.

24.BENEDEC, D., HANGANU, D., FILIP, L., ONIGA, I., TIPERCIUC, B., OLAH, N.-K., GHELDIU, A.-M., RAITA, O., VLASE, L., FARMACIA, 65, 2, 2017, p. 252.

25.PREDESCU, N. C., PAPUC, C. NICORESCU, V., GAJ AILA, I., GORAN, G. V., PETCU, C. D., STEFAN, G., Rev. Chim. (Bucharest), 67, no. 10, 2016, p. 1922.

Manuscript received: 26.06 .2018 